\title{
Predicting the Temperature and Composition - Dependent Density and Viscosity of Diesel Fuel - Ethanol Blends
}

\author{
Adrian Todoruț ${ }^{1}$, Andreia Molea$^{1}$, István Barabás ${ }^{1 *}$ \\ 1 Department of Automotive Engineering and Transports, Faculty of Automotive, Mechatronics and Mechanical Engineering, \\ Technical University of Cluj-Napoca, 400641 Cluj-Napoca, Bulevardul Muncii 103-105, Romania \\ *Corresponding author, e-mail: istvan.barabas@auto.utcluj.ro
}

Received: 29 July 2019, Accepted: 21 October 2019, Published online: 02 December 2019

\begin{abstract}
Density and viscosity are very important fuel properties which have a major influence not only on the fuel production, transportation and distribution processes but also on the processes that take place in an internal combustion engine. Developing robust and high precision density and viscosity models for stabilized diesel fuel - ethanol blends helps the production of fuel to adhere to the quality requirements regarding density and viscosity and the modeling and simulation of injection and combustion processes. For modeling the density and the viscosity of diesel fuel - ethanol blends, five mixtures were prepared with ethanol content up to $15 \%$ ( $v / v$ ) and were stabilized by adding tetrahydrofuran as a surfactant at room temperature. The temperature-dependent density and viscosity of the blends were measured at four different temperatures $\left(0,15,40\right.$ and $\left.50{ }^{\circ} \mathrm{C}\right)$ using an SVM 3000 type apparatus. Based on experimental data, several mixing rules were fitted to them and three new models were developed, of which two need only one experimental value. These models yield very good accuracies, presenting average relative deviations of $0.0604 \%$ in the case of density and $3.8931 \%$ in the case of viscosity.
\end{abstract}

Keywords

diesel - ethanol fuel blends, stable ternary blends, mathematical models, density, viscosity

\section{Introduction}

Nowadays, transportation is one of the most pollutant sector in urban environment because of the fossil nature of the energy source and the process of transformation of the chemical energy into mechanical work [1]. Another concern is the petrol reserves which are more and more limited and expensive [2]. On the one hand, in spite of the current development of alternative drivetrains of the automotive vehicles (hybrid, plug-in hybrid and electric), internal fossil-fueled combustion engines (ICE) will remain the most used propellent [3] for a while, even if they are banned in large urban agglomerations, like Stuttgart, Hamburg, Paris, Madrid, Paris, Madrid, Copenhagen, etc. [4]. On the other hand, even if there are several technological approaches to reduce the fuel consumption and environmental pollution caused by fossil fuels, they have their costs on individuals and the society as well, which is a rational contradiction between transportation and environmental protection [5]. Meanwhile, identifying more environmentally friendly fuels for ICE is the key for the transition from fossil fuels to electricity or some combination of them. Blends of diesel fuel - ethanol appear to be one of the potential solutions which could be used for fueling diesel engines [6-8].

Developing precise and robust models to describe the properties of newly developed fuels for ICE is compulsory not only in order to predict all parameters of the production, storage and transportation of the fuel [9], but also to describe thermodynamic processes related to internal combustion engines [10].

Density is one of the most important properties of the fuels because it influences its production, transportation and distribution processes, and all the processes which occur in an ICE [11]. Apart from viscosity, surface tension, and vapor pressure, density determines the fuel spray quality and thus the combustion and emission characteristics of the engine [12]. Fuel density is the main property that influences the amount of injected fuel mass and therefore, the fuel consumption [11].

Viscosity affects the quality of the fuel spray formation, the fuel droplet size, the penetration of the fuel jet and, 
ultimately, the quality of the combustion which influences the efficiency and emission level of an ICE [13]. Fuel viscosity influences the necessary pumping power, fuel leakage losses in the fuel pump and the fuel lubricity [14].

Ethanol has a very limited miscibility in a diesel fuel. Using proper surfactants, like methyl esters or long-chain alcohols, their miscibility can be improved [15].

THF was identified as an effective co-solvent for diesel-ethanol blends and it can be obtained at low cost from agricultural waste materials [16]. Research has pointed out that blending THF with other fuels, like algae biodiesel [17] or soybean oil [18], reduces the emissions from the diesel engine.

There are some concerns about the reduction of the flash point and the cetane number of the blends owing to the low flashpoint and cetane number of ethanol and THF [19]. Whereas the flash point of the blend cannot be easily increased, the cetane number can be restored by using a small amount of cetane improver additive [20].

Including a third component into the diesel fuel - ethanol blends makes the classical modeling methods more difficult. The density and the viscosity of diesel fuel - ethanol blends were investigated in many studies but, to the best of our knowledge, models for densities and viscosities of diesel fuels - ethanol - surfactant blends, which take into account, in the same time, both the composition and the temperature of the blends, have not been studied yet.

The main aim of this work is to develop proper mathematical models which are able to accurately describe both the temperature and composition dependences of densities and absolute (dynamic) viscosities of the diesel fuel - ethanol blends stabilized by a surfactant.

\section{Materials and methods}

In this research commercially available diesel fuel, ethanol with $99.2 \%$ purity and tetrahydrofuran (THF) having $99.5 \%$ concentration were used. The diesel fuel used in this research followed the European standard EN 590 for winter fuel and its main properties related of this work were evaluated using an IROX Diesel type apparatus. Its aromatic hydrocarbon content was $42.9 \%(\mathrm{v} / \mathrm{v})$, whereby $7.4 \%(\mathrm{v} / \mathrm{v})$ was polyaromatic hydrocarbon and it included $0.2 \%(\mathrm{v} / \mathrm{v})$ biodiesel.

Initially, using class A precision pipettes and graded cylinders, five diesel fuel - ethanol blends were prepared at room temperature $\left(20^{\circ} \mathrm{C}\right)$, containing $2,5,8,10$ and $15 \%(\mathrm{v} / \mathrm{v})$ ethanol. These blends were homogenized in a closed Berzelius beaker with a magnetic stirrer at $400 \mathrm{r} / \mathrm{min}$ for 30 minutes and in an ultrasonic bath for a further 20 minutes. After the preparation, the blends were monitored for three days in order to evaluate their stability and miscibility. In the case of the blends which presented any phase separation, depending on the quantity of separated ethanol, $0.5 \mathrm{~mL}, 1.0 \mathrm{~mL}$ or $2.0 \mathrm{~mL}$ of tetrahydrofuran were added as a surfactant into the blends. These new blends were homogenized and monitored again in the same way as aforementioned. These steps were repeated until all the blends became stable. At this point, the compositions of the blends were recalculated and expressed in relative volume of diesel fuel, ethanol and tetrahydrofuran.

The temperature dependent densities and viscosities of the components and the blends were measured by using an SVM 3000 type apparatus. It measured the absolute viscosity and density (ASTM D7042 [21] and ISO 12185 [22]) and calculated the kinematic viscosity. The uncertainties of the density and viscosity measurements at the $95 \%$ confidence level with a coverage factor of $k=2$ were estimated $0.02 \%$ for density and $0.35 \%$ for viscosity.

Prior to the measurements, the viscometer was cleaned with a proper solvent, it was recalibrated with standardized fluids and finally it was dried with air. All the measurements were repeated three times and their average values were considered. Because of the high volatility of the THF (its boiling point is $64{ }^{\circ} \mathrm{C}$ ) the viscosity and density measurements were carried out up to $50{ }^{\circ} \mathrm{C}$ at four temperatures: $0{ }^{\circ} \mathrm{C}$ - which evaluates the cold flow properties, $15{ }^{\circ} \mathrm{C}$ - the standard temperature for density measurement, $40{ }^{\circ} \mathrm{C}$ - the standard temperature for viscosity measurement) and $50{ }^{\circ} \mathrm{C}-$ the maximum temperature for accurate measurements.

The measured data were processed, and the mathematical models were developed with the aid of ORIGIN software, in the case of the components, and EXCEL-Solver software by minimizing the Average Relative Deviation of the models, in the case of the blends.

The accuracy of the developed models was evaluated based on their Average Relative Deviation (ARD), Standard Deviation (SD), and correlation coefficient $(R)$ which are defined by the following equations:

$$
\begin{aligned}
& \mathrm{ARD}=\frac{100}{N} \sum_{i=1}^{N} \frac{\mid \text { est }_{i}-\text { exptl }_{i} \mid}{\text { exptl }_{i}} \%, \\
& \mathrm{SD}=\sqrt{\frac{\sum_{i=1}^{N}\left(\text { est }_{i}-\text { exptl }_{i}\right)^{2}}{N-m}},
\end{aligned}
$$




$$
R=\frac{\sum_{i=1}^{N}\left(\text { exptl }_{i}-\overline{\text { exptl }_{i}}\right)\left(e s t_{i}-\overline{e^{2} t_{i}}\right)}{\sqrt{\sum_{i=1}^{N}\left(\text { exptl }_{i}-\overline{\operatorname{exptl}_{i}}\right)^{2} \sum_{i=1}^{N}\left(e s t_{i}-\overline{e^{2} t_{i}}\right)^{2}}},
$$

where exptl and $_{\text {est }}$ are the measured and estimated values, $\overline{\text { exptl }}$ and $\overline{\text { est }}$ are the averages of the measured and predicted values, $N$ represents the number of experimental values and $m$ is the number of model parameters.

\section{Experimental results}

After the prepared blends had become stable, their composition was changed because of the THF addition. The final compositions of the stabilized blends are presented in Table 1. The average ratio of THF to ethanol to form stable blends at room temperature was 1:2.2.

The measured temperature-dependent densities and viscosities of the blends are given in Table 2. The maximum Standard Deviations of the experimental measurements were 0.0001 in the case of the density and 0.028 in the case of absolute viscosity.

Table 1 The composition of the stabilized diesel - ethanol - THF blends

\begin{tabular}{lccccc}
\hline Components & \multicolumn{5}{c}{ Initial concentration, \% (v/v) } \\
\hline Ethanol & 2 & 5 & 8 & 10 & 15 \\
\hline \multicolumn{5}{c}{ Concentrations after stabilization, \% (v/v) } \\
Diesel & 97.512 & 92.683 & 87.559 & 84.791 & 79.017 \\
Ethanol & 1.990 & 4.878 & 7.614 & 9.421 & 13.944 \\
THF & 0.498 & 2.439 & 4.827 & 5.787 & 7.039 \\
\hline
\end{tabular}

As the density of THF is higher than the density of the other two components it compensates the lower density of the ethanol. Consequently, the density of the blends fulfills the EN 590 standard requirement $(0.820-0.845 \mathrm{~g} / \mathrm{mL}$ at $15^{\circ} \mathrm{C}$ ). In the case of viscosity, only the blends containing up to $5 \%(\mathrm{v} / \mathrm{v})$ ethanol meet the viscosity requirement $\left(2.0-4.5 \mathrm{~mm}^{2} / \mathrm{s}\right.$ at $\left.40{ }^{\circ} \mathrm{C}\right)$ for diesel fuel; for the rest of the blends it falls below $2.0 \mathrm{~mm}^{2} / \mathrm{s}$. The maximum decrease is $14 \%$ and it belongs to the blend with $15 \%$ ethanol.

\section{Models for fuel blends properties}

\subsection{Models for predicting the densities of the blends}

In our previous work [23] we concluded that a quadratic model was a good estimator for modeling the temperature-dependent density of the components:

$\rho(t)=a_{0}+a_{1} t+a_{2} t^{2}$

where $\rho(t)(\mathrm{g} / \mathrm{mL})$ is the density, $t\left({ }^{\circ} \mathrm{C}\right)$ is the temperature, $a_{0}, a_{1}$ and $a_{2}$ are parameters of the regressions. The calculated values of the regression parameter for each compound and the precision of the models are presented in Table 3.

It can be observed that all the models describe the temperature-dependent densities of the components with a very high fidelity, having the regression coefficient almost 1 and a very low Average Relative Deviation (below $0.5 \%$ ).

One of the widely used methods to estimate properties of liquid blends is based on the mixing of the properties of its components by using a suitable mixing rule.

Table 2 The measured densities and viscosities of diesel - ethanol - THF blends

\begin{tabular}{|c|c|c|c|c|c|c|c|c|}
\hline \multirow{2}{*}{$\begin{array}{l}\text { Temp., } \\
{ }^{\circ} \mathrm{C}\end{array}$} & \multicolumn{3}{|c|}{ Components } & \multicolumn{5}{|c|}{ Initial concentration, $\%(\mathrm{v} / \mathrm{v})$} \\
\hline & Diesel & Ethanol & THF & 2 & 5 & 8 & 10 & 15 \\
\hline \multicolumn{9}{|c|}{ Density, $\rho, \mathrm{g} / \mathrm{cm}^{3}$} \\
\hline 0 & 0.8522 & 0.8160 & 0.9100 & 0.8393 & 0.8385 & 0.8391 & 0.8393 & 0.8388 \\
\hline 15 & 0.8416 & 0.8034 & 0.8937 & 0.8286 & 0.8273 & 0.8278 & 0.8278 & 0.8270 \\
\hline 40 & 0.8240 & 0.7816 & 0.8661 & 0.8109 & 0.8088 & 0.8087 & 0.8085 & 0.8073 \\
\hline 50 & 0.8170 & 0.7728 & 0.8535 & 0.8038 & 0.8013 & 0.8011 & 0.8007 & 0.7994 \\
\hline \multicolumn{9}{|c|}{ Absolute viscosity, $\eta, \mathrm{mPa} \cdot \mathrm{s}$} \\
\hline 0 & 6.7785 & 2.0847 & 0.6102 & 5.2687 & 4.5151 & 4.1170 & 3.9289 & 3.8771 \\
\hline 15 & 4.2290 & 1.4901 & 0.5389 & 3.3658 & 2.9069 & 2.6540 & 2.5221 & 2.4241 \\
\hline 40 & 2.2687 & 0.9061 & 0.4381 & 1.9244 & 1.6601 & 1.5422 & 1.4705 & 1.3857 \\
\hline 50 & 1.8587 & 0.7121 & 0.4041 & 1.6032 & 1.3730 & 1.2859 & 1.2334 & 1.1564 \\
\hline \multicolumn{9}{|c|}{ Kinematic viscosity, $v, \mathrm{~mm}^{2} / \mathrm{s}$} \\
\hline 0 & 7.9540 & 2.5547 & 0.6705 & 6.2778 & 5.3851 & 4.9064 & 4.6814 & 4.6221 \\
\hline 15 & 5.0247 & 1.8548 & 0.6030 & 4.0618 & 3.5135 & 3.2060 & 3.0467 & 2.9311 \\
\hline 40 & 2.7532 & 1.1593 & 0.5058 & 2.3733 & 2.0527 & 1.9069 & 1.8187 & 1.7164 \\
\hline 50 & 2.2750 & 0.9215 & 0.4734 & 1.9945 & 1.7135 & 1.6053 & 1.5404 & 1.4466 \\
\hline
\end{tabular}


Table 3 Parameters and accuracies of density models of the components

\begin{tabular}{lccc}
\hline Parameters & Diesel & Ethanol & Tetrahydrofuran \\
\hline$a_{0}$ & 0.8522 & 0.8160 & 0.90987 \\
$a_{1}$ & $7.0827 \cdot 10^{-4}$ & $-8.3518 \cdot 10^{-4}$ & -0.0010 \\
$a_{2}$ & $8.3596 \cdot 10^{-8}$ & $-5.9685 \cdot 10^{-7}$ & $-1.8638 \cdot 10^{-6}$ \\
$R$ & 0.9999 & 0.9999 & 0.9999 \\
$\mathrm{SD}, \mathrm{g} / \mathrm{mL}$ & $3.7009 \cdot 10^{-6}$ & $4.0200 \cdot 10^{-5}$ & 0.0003 \\
$\mathrm{ARD}, \%$ & 0.0004 & 0.0048 & 0.0300 \\
\hline
\end{tabular}

Kay's Mixing Rule describes the properties of blends by the concentration-weighted sum of the properties of the components. For density, the Kay's Mixing Rule (KMR) is [11, 24]:

$\rho_{e s t}=f_{D} \rho_{D}(t)+f_{E} \rho_{E}(t)+f_{T} \rho_{T}(t)$,

where $\rho_{\text {est }}(t)(\mathrm{g} / \mathrm{mL})$ is the predicted density of the blend, $\rho_{D}(t), \rho_{E}(t)$ and $\rho_{T}(t)(\mathrm{g} / \mathrm{mL})$ are the temperature dependent densities of diesel, ethanol and THF, given by Eq. (4), $f_{D}, f_{E}$ and $f_{T}$ are the volume fraction of the diesel, ethanol and THF.

Since Eq. (5) has a positive error of $1.6 \%$ (Fig. 1 a), Table 4), its precision must be improved. In order to fine
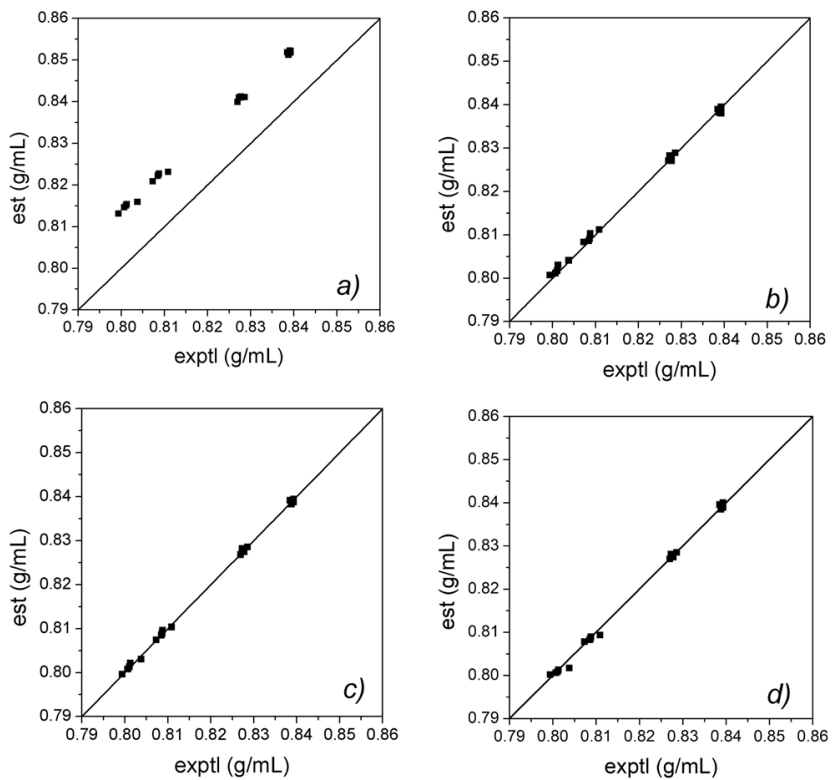

Fig. 1 The precisions of the densities models: a) Eq. (5); b) Eq. (6); c) Eq. (7); d) Eq. (9) tune the model, the contributions of the components to the density of the blend have to be weighted [24]:

$\rho_{\text {est }}(t)=k_{D} f_{D} \rho_{D}(t)+k_{E} f_{F} \rho_{E}(t)+k_{T} f_{T} \rho_{T}(t)$,

were $k_{D}, k_{E}$ and $k_{T}$ are weighting parameters. This model improves the density prediction accuracy, having an ARD of 0.0826 (Fig. 1 b) and Table 4).

The precision of Eq. (6) can be further improved by introducing a constant term, $k_{0}$ :

$\rho_{\text {est }}(t)=k_{D} f_{D} \rho_{D}(t)+k_{E} f_{E} \rho_{E}(t)+k_{T} f_{T} \rho_{T}(t)+k_{0}$.

This proposed model halves the ARD of the previous model (Fig. 1 c), Table 4). As the influence of the temperature is a linear one, it can be modeled as monomial:

$\rho_{\text {est }}(t)=k_{D} f_{D} \rho_{D}(t)+k_{E} f_{E} \rho_{E}(t)+k_{T} f_{T} \rho_{T}(t)+k_{1} t+k_{0}$,

where $k_{1}$ and $k_{0}$ are constants. The precision of this model is comparable with the precision of Eq. (7).

Usually, only the density at $15^{\circ} \mathrm{C}$ of the diesel fuel is known and the densities of the other two components are material constants. In this case the temperature- and composition - dependent densities of the blends can be estimated using the following model:

$\rho_{e s t}(t)=k_{D} f_{D} \rho_{D}^{15}+k_{E} f_{E} \rho_{E}^{15}+k_{T} f_{T} \rho_{T}^{15}+k_{1} t+k_{0}$,

where $\rho_{D}^{15}, \rho_{E}^{15}$ and $\rho_{T}^{15}$ are the densities of diesel fuel, ethanol and THF respectively. As it is shown in Fig. $1 \mathrm{~d}$ ) and Table 4, the precision of this model is lower than the precision of the previous two models, but it has the important advantage of using only one experimental value (the density of the diesel fuel at $15^{\circ} \mathrm{C}$ ).

\subsection{Models for predicting the viscosities of the blends}

The temperature dependence of the absolute viscosity of the components can be modeled by the Vogel-FulcherTammann (VFT) equation [25]:

$\ln [(t)]=A+B /(C+t)$,

Table 4 The constants and the accuracies of the models described by Eqs. (5)-(9)

\begin{tabular}{ccccccccc}
\hline Eq. & $k_{D}$ & $k_{E}$ & $k_{T}$ & $k_{1}$ & $k_{0}$ & $\mathrm{ARD}, \%$ & $\mathrm{SD}, \mathrm{g} / \mathrm{mL}$ & $R$ \\
\hline$(5)$ & - & - & - & - & - & 1.6163 & 0.0162 & 0.9993 \\
$(6)$ & 0.9849 & 1.0526 & 0.8618 & - & - & 0.0826 & 0.0147 & 0.9992 \\
$(7)$ & 0.4125 & 0.0081 & 0.0022 & - & 0.4964 & 0.0444 & 0.0149 & 0.9995 \\
$(8)$ & 0.01634 & 0.0078 & 0.0023 & -0.0008 & 0.8264 & 0.0595 & 0.0151 & 0.9999 \\
$(9)$ & 0.0157 & 0.0082 & 0.0023 & -0.0008 & 0.8270 & 0.0604 & 0.0151 & 0.9989 \\
\hline
\end{tabular}


where $\eta(t)(\mathrm{mPa} \cdot \mathrm{s})$ is the absolute viscosity of the component at temperature $t\left({ }^{\circ} \mathrm{C}\right)$ and $A, B$ and $C$ are parameters which can be calculated by measuring the viscosity at least at three different temperatures. The values of the regression parameters and the precision of the models are given in Table 5 .

As in the case of the densities, the absolute viscosities of the blends can be described using Kay's Mixing Rule which is a simplified Grunberg-Nissan model [25, 26]:

$$
\ln \left[\eta_{e s t}(t)\right]=f_{D} \ln \left[\eta_{D}(t)\right]+f_{E} \ln \left[\eta_{E}(t)\right]+f_{T} \ln \left[\eta_{T}(t)\right],
$$

where $\eta_{\text {est }}(t)(\mathrm{mPa} \cdot \mathrm{s})$ is the predicted viscosity of the blend, $\eta_{D}(t), \eta_{E}(t)$ and $\eta_{T}(t),(\mathrm{mPa} \cdot \mathrm{s})$ are the temperature dependent viscosities of diesel, ethanol and THF, given by Eq. (10), $f_{D}, f_{E}$ and $f_{T}$ are the volume fraction of the diesel, ethanol and THF respectively.

As shown in Fig. 2 a) and Table 6, Eq. (11) has a large positive error of $27 \%$. Das et al. [27] proposed an improved

Table 5 Parameters and accuracies of viscosity models of the components

\begin{tabular}{lccc}
\hline Parameters & Diesel & Ethanol & Tetrahydrofuran \\
\hline$A$ & -3.2261 & -7.0357 & -6.3491 \\
$B$ & 762.0029 & 2510.4069 & 3874.8473 \\
$C$ & 148.2529 & 322.9650 & 661.5741 \\
$R$ & 0.9999 & 0.9999 & 0.9999 \\
$\mathrm{SD}, \mathrm{mPa} \cdot \mathrm{s}$ & $7.3636 \cdot 10^{-3}$ & $33.2516 \cdot 10^{-3}$ & $2.5350 \cdot 10^{-3}$ \\
$\mathrm{ARD}, \%$ & 0.0004 & 0.0048 & 0.0300 \\
\hline
\end{tabular}
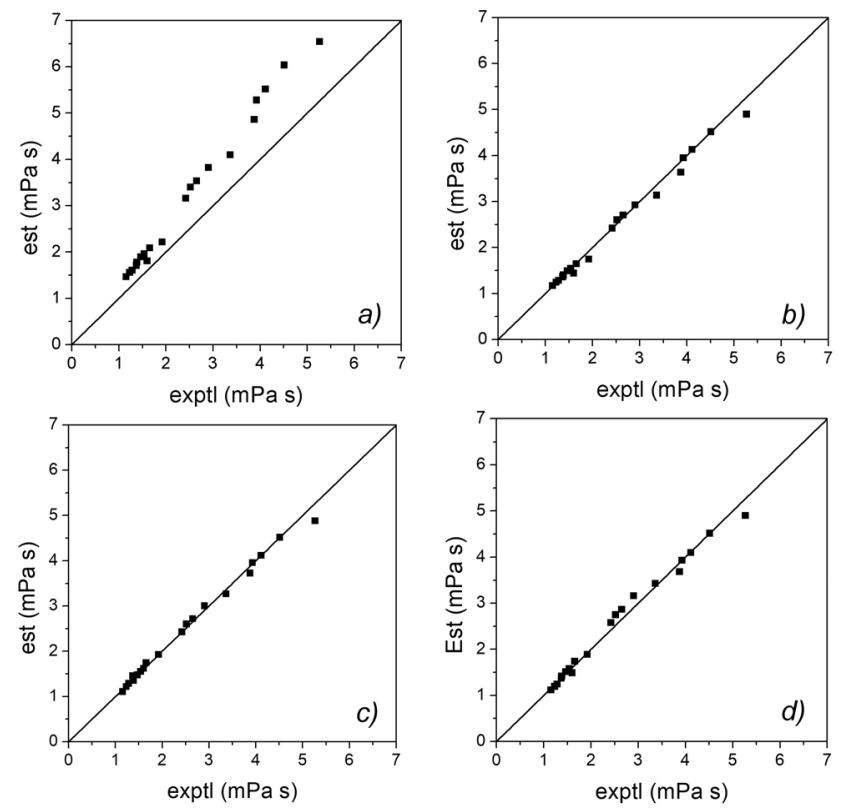

Fig. 2 The precisions of the viscosity models: a) Eq. (11); b) Eq. (12); c) Eq. (13); d) Eq. (14). model for the viscosity of a ternary blend by adding a fractional term to Eq. (11):

$$
\begin{aligned}
\ln \left[\eta_{\text {est }}(t)\right] & =f_{D} \ln \left[\eta_{D}(t)\right]+f_{E} \ln \left[\eta_{E}(t)\right]+f_{T} \ln \left[\eta_{T}(t)\right] \\
& +\frac{M_{0}}{t+M_{1}},
\end{aligned}
$$

where $M_{0}$ and $M_{1}$ are constants. By minimizing the Average Relative Deviation (ARD) of the prediction model, the resulted values of these constants are $M_{0}=-52.0906$ and $M_{1}=-179.5159$. This model improves the precision of the prediction, mainly the ARD which drops more than three times (Fig. 2 b), Table 6).

Another way to improve the precision of Eq. (11) is proposed in $[11,24]$ by using weighting factors:

$$
\begin{aligned}
\ln \left[\eta_{\text {est }}(t)\right] & =k_{D} f_{D} \ln \left[\eta_{D}(t)\right]+k_{E} f_{E} \ln \left[\eta_{E}(t)\right] \\
& +k_{T} f_{T} \ln \left[\eta_{T}(t)\right],
\end{aligned}
$$

where all the notations have the same meaning as defined above. As illustrated in Fig. 2 c) and evaluated in Table 6, the precision of this model is good for the proposed applications.

Usually, the viscosity of the diesel fuel is given at the temperature of $40{ }^{\circ} \mathrm{C}$. Therefore, a model which only uses the viscosities of the components at this standardized temperature can be more useful in most of the practical applications:

$$
\begin{aligned}
\ln \left[\eta_{\text {est }}(t)\right] & =k_{D} f_{D} \ln \left(\eta_{D}^{40}\right)+k_{E} f_{E} \ln \left(\eta_{E}^{40}\right) \\
& +k_{T} f_{T} \ln \left(\eta_{T}^{40}\right)+k_{0} t
\end{aligned}
$$

where $\eta_{D}^{40}, \eta_{E}^{40}$ and $\eta_{T}^{40}$ are the absolute viscosities of the components at $40{ }^{\circ} \mathrm{C}$, all other notations have the same meaning as they were defined above. This model delivers a lower precision than Eq. (13) (Fig. 2 d), Table 6), but it is very practical.

The kinematic viscosity of the blends can be calculated as a ratio of absolute viscosity to density. Using Eq. (13) for the absolute viscosity and Eq. (8) for the density, the resulted values of the kinematic viscosity are in very good agreement with the experimental values $(\mathrm{ARD}=2.2579 \%$, Fig. 3 a)). Even when the less precise models (Eqs. (9) and (14)) are used, the precision of the resulted kinematic viscosities remains acceptable $(\mathrm{ARD}=3.6813 \%$, Fig. 3 b) $)$.

\subsection{Validation of the developed models for other blends}

All the constants of the developed models were determined for the diesel fuel, ethanol and THF used in this work. In order to validate the models, they were tested with viscosity and density data obtained from the existing 


\begin{tabular}{cccccccc}
\multicolumn{8}{c}{ Table 6 The constants and the precision of the models described by Eqs. (11)-(14) } \\
\hline Eq. & $k_{D}$ & $k_{E}$ & $k_{T}$ & $k_{0}$ & ARD, \% & SD, mPa·s & $R$ \\
\hline$(11)$ & - & - & - & - & 27.1054 & 1.4859 & 0.9958 \\
$(12)$ & - & - & - & - & 7.8774 & 1.2105 & 0.9961 \\
$(13)$ & 0.8412 & 1.6846 & 3.7659 & - & 2.2208 & 1.2086 & 0.9972 \\
$(14)$ & 1.9665 & -9.7039 & 2.3180 & -0.02387 & 3.8931 & 1.2166 & 0.9939 \\
\hline
\end{tabular}
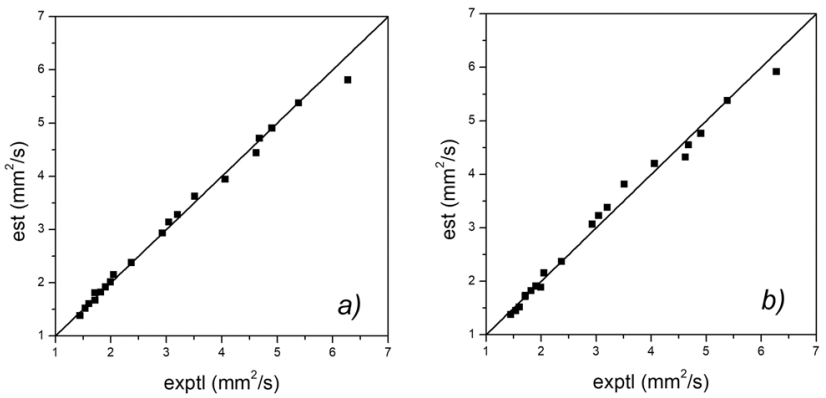

Fig. 3 The precisions of the predicted kinematic viscosity:

a) Eq. (13)/Eq. (8); b) Eq. (14)/Eq. (9).

literature. Unfortunately, relevant literature provides very few data on the density and viscosity of diesel-ethanol-tetrahydrofuran blends. Moreover, these data are published for one single value of the temperature and not for an interval, as it is the case of the present study.

The validation of the density models based on data from [28] is presented in Table 7. It can be observed that the density models developed in this research provide a very good precision. The model given by Eq. (8) has the best precision, followed by the models described by Eq. (9) and Eq. (7).

In terms of viscosity, using the data published in the same source [28], the models for absolute viscosity have been verified, and the results are presented in Table 8 . It can be noticed that the viscosity models developed in the present study (Eqs. (13) and (14)) deliver a good accuracy in the case of other types of blends, better than models from the specialized literature (Eqs. (11) and (12)).

\section{Conclusions}

The temperature- and composition - dependent density and viscosity of diesel fuel - ethanol blends containing up to $15 \%(\mathrm{v} / \mathrm{v})$ ethanol were modeled in the temperature range of $0-50{ }^{\circ} \mathrm{C}$. Based on our findings, the following conclusions can be framed:

- Blends containing more than $2 \%$ ethanol are not stable at room temperature, they start separating within a few minutes after the homogenization process stops. Above this concentration they require a surfactant, like tetrahydrofuran. The necessary quantity of surfactant increases as the ethanol quantity increases in the blend.

- In the case of the density of the blends, the weighted Kay's rule is in good agreement with the experimental data.

- The weighted Key's rule, completed by a monomial, delivers a very good prediction of the temperature and composition dependent viscosity.

- Given that density and viscosity are material properties in the case of ethanol and tetrahydrofuran, the models described by Eqs. (9) and (14) are able to describe these quantities as a function of their temperature and composition using a single

Table 7 Density models validation

\begin{tabular}{llllccc}
\hline \multirow{2}{*}{ Components } & \multicolumn{5}{c}{ Density at $20^{\circ} \mathrm{C}, \mathrm{g} / \mathrm{cm}^{3}$} \\
Diesel & Ethanol & THF & & Eq. (7) & Eq. (8) & Eq. (9) \\
\hline 97.4 & 2.0 & 0.6 & 0.8250 & 0.8332 & 0.8239 & 0.8240 \\
95.0 & 4.0 & 1.0 & 0.8257 & 0.8251 & 0.8237 & 0.8238 \\
92.0 & 6.0 & 2.0 & 0.8260 & 0.8148 & 0.8234 & 0.8236 \\
87.6 & 8.0 & 4.4 & 0.8263 & 0.7998 & 0.8230 & 0.8232 \\
85.0 & 10.0 & 5.0 & 0.8243 & 0.7910 & 0.8228 & 0.8230 \\
80.0 & 15.0 & 5.0 & 0.8208 & 0.7740 & 0.8224 & 0.8227 \\
\hline ARD, $\%$ & & & & 2.5622 & $2.03 \cdot 10^{-5}$ & 0.0023 \\
SD & & & & 0.0178 & 0.0016 & 0.0016 \\
R & & & & 0.9059 & 0.9803 & 0.8754 \\
\hline
\end{tabular}


Table 8 Viscosity models validation

\begin{tabular}{|c|c|c|c|c|c|c|c|}
\hline \multirow{2}{*}{\multicolumn{3}{|c|}{ Components }} & \multicolumn{5}{|c|}{ Absolute viscosity at $40{ }^{\circ} \mathrm{C}, \mathrm{mPa} \cdot \mathrm{s}$} \\
\hline & & & \multirow[t]{2}{*}{ Measured } & \multicolumn{4}{|c|}{ Calculated } \\
\hline Diesel & Ethanol & THF & & Eq. (11) & Eq. (12) & Eq. (13) & Eq. (14) \\
\hline 97.4 & 2.0 & 0.6 & 2.1179 & 2.2056 & 2.1942 & 1.9141 & 1.9536 \\
\hline 95.0 & 4.0 & 1.0 & 1.9865 & 2.1513 & 1.3734 & 1.8532 & 1.9012 \\
\hline 92.0 & 6.0 & 2.0 & 1.8549 & 2.0777 & 1.3875 & 1.7539 & 1.8116 \\
\hline 87.6 & 8.0 & 4.4 & 1.7868 & 1.9609 & 1.3734 & 1.5740 & 1.6430 \\
\hline 85.0 & 10.0 & 5.0 & 1.6581 & 1.9064 & 1.3734 & 1.5125 & 1.5877 \\
\hline 80.0 & 15.0 & 5.0 & 1.5772 & 1.8209 & 1.3734 & 1.4491 & 1.5366 \\
\hline ARD, $\%$ & & & & 10.7676 & 18.8165 & 8.4319 & 4.8758 \\
\hline SD & & & & 0.1961 & 0.3110 & 0.2039 & 0.1856 \\
\hline $\mathrm{R}$ & & & & 0.9838 & 0.7023 & 0.9757 & 0.9729 \\
\hline
\end{tabular}

experimental value (the density of the diesel fuel at $15^{\circ} \mathrm{C}$ in the case of Eq. (9) and its viscosity at $40{ }^{\circ} \mathrm{C}$ in the case of Eq. (14), respectively).

- Calculating the kinematic viscosity by using the proposed density and viscosity models delivers very precise results in good agreement with the experimental values.

- The density of the blends fulfills the EN 590 standard requirement, but only blends with up to $5 \%$ ethanol meet the viscosity limits imposed by the same standard.

\section{References}

[1] Szabados, G., Bereczky, Á. "Comparison Tests of Diesel, Biodiesel and TBK-Biodiesel", Periodica Polytechnica Mechanical Engineering, 59(3), pp. 120-125, 2015. https://doi.org/10.3311/PPme.7989

[2] Rakopoulos, C. D., Rakopoulos, D. C., Kosmadakis, G. M., Papagiannakis, R. G. "Experimental comparative assessment of butanol or ethanol diesel-fuel extenders impact on combustion features, cyclic irregularity, and regulated emissions balance in heavy-duty diesel engine", Energy, 174, pp. 1145-1157, 2019. https://doi.org/10.1016/j.energy.2019.03.063

[3] Zöldy, M. "Investigation of Correlation Between Diesel Fuel Cold Operability and Standardized Cold Flow Properties", Periodica Polytechnica Transportation Engineering, 2019. https://doi.org/10.3311/PPtr.14148

[4] Greim, H. "Diesel engine emissions: are they no longer tolerable?", Archives of Toxicology, 93(9), pp. 2483-2490, 2019. https://doi.org/10.1007/s00204-019-02531-5

[5] Zöldy, M., Török, Á. "Road Transport Liquid Fuel Today and Tomorrow: Literature Overview", Periodica Polytechnica Transportation Engineering, 43(4), pp. 172-176, 2015. https://doi.org/10.3311/PPtr.8095

[6] Zöldy, M. "Ethanol-biodiesel-diesel blends as a diesel extender option on compression ignition engines", Transport, 26(3), pp. 303-309, 2011.

https://doi.org/10.3846/16484142.2011.623824
- The developed models can be used in the proposed applications.

The authors intend to develop further models to describe other properties of diesel-ethanol-THF blends in order to use them in fuel injection and combustion modeling and simulation. Furthermore, preliminary internal combustion engine tests have been already done with promising results.

[7] Burnete, N. V., Filip, N., Barabás, I. "Diesel-ethanol blends and their use in diesel engines", Romanian Journal of Automotive Engineering, 21(3), pp. 89-106, 2015. [online] Available at: http://www.ingineria-automobilului.ro/reviste/RoJAE_201509_03. pdf\#page=15 [Accessed: 28 July 2019]

[8] Tutak, W., Lukács, K., Szwaja, S., Bereczky, Á. "Alcohol-diesel fuel combustion in the compression ignition engine", Fuel, 154, pp. 196-206, 2015. https://doi.org/10.1016/j.fuel.2015.03.071

[9] Ramírez-Verduzco, L. F., García-Flores, B. E., RodríguezRodríguez, J. E., del Rayo Jaramillo-Jacob, A. "Prediction of the density and viscosity in biodiesel blends at various temperatures", Fuel, 90(5), pp. 1751-1761, 2011. https://doi.org/10.1016/j.fuel.2010.12.032

[10] Lapuerta, M., Rodríguez-Fernández, J., Fernández-Rodríguez, D., Patiño-Camino, R. "Modeling viscosity of butanol and ethanol blends with diesel and biodiesel fuels", Fuel, 199, pp. 332-338, 2017. https://doi.org/10.1016/j.fuel.2017.02.101

[11] Pratas, M. J., Freitas, S. V. D., Oliveira, M. B., Monteiro, S. C., Lima, Á. S., Coutinho, J. A. P. "Biodiesel Density: Experimental Measurements and Prediction Models", Energy Fuels, 25(5), pp. 2333-2340, 2011. https://doi.org/10.1021/ef2002124 
[12] Nita, I., Geacai, S., Iulian, O. "Measurements and correlations of physico-chemical properties to composition of pseudo-binary mixtures with biodiesel", Renewable Energy, 36(12), pp. 3417-3423, 2011. https://doi.org/10.1016/j.renene.2011.05.020

[13] Alptekin, E., Canakci, M. "Characterization of the key fuel properties of methyl ester-diesel fuel blends", Fuel, 88(1), pp. 75-80, 2009. https://doi.org/10.1016/j.fuel.2008.05.023

[14] Anand, K., Ranjan, A., Mehta, P. S. "Estimating the Viscosity of Vegetable Oil and Biodiesel Fuels", Energy Fuels, 24(1), pp. 664-672, 2010. https://doi.org/10.1021/ef900818s

[15] Liu, H., Hu, B., Jin, C. "Effects of different alcohols additives on solubility of hydrous ethanol/diesel fuel blends", Fuel, 184, pp. 440-448, 2016. https://doi.org/10.1016/j.fuel.2016.07.037

[16] Letcher, T. M. "Diesel blends for diesel engines", South African Journal of Science, 79, pp. 4-7, 1983.

[17] Karthikeyan, S., Prathima, A. "Engine emission characteristics of algal biofuel with micro emulsion", Energy Sources, Part A: Recovery, Utilization, and Environmental Effects, 38(24), pp. 3661-3667, 2016.

https://doi.org/10.1080/15567036.2016.1163440

[18] Jin, C., Zhang, X., Geng, Z., Pang, X, Wang, X., Ji, J., Wang, G., Liu, H. "Effects of various co-solvents on the solubility between blends of soybean oil with either methanol or ethanol", Fuel, 244, pp. 461-471, 2019. https://doi.org/10.1016/j.fuel.2019.01.187

[19] Pradelle, F., Braga, S. L., de Aguiar Martins, A. R. F., Turkovics, F., Pradelle, R. N. C. "Experimental assessment of some key physicochemical properties of diesel-biodiesel-ethanol (DBE) blends for use in compression ignition engines", Fuel, 248, pp. 241-253, 2019. https://doi.org/10.1016/j.fuel.2019.03.087

[20] Shahir, S. A., Masjuki, H. H., Kalam, M. A., Imran, A., Rizwanul Fattah, I. M., Sanjid, A. "Feasibility of diesel-biodiesel-ethanol/ bioethanol blend as existing CI engine fuel: An assessment of properties, material compatibility, safety and combustion", Renewable and Sustainable Energy Reviews, 32, pp. 379-395, 2014.

https://doi.org/10.1016/j.rser.2014.01.029
[21] American Society for Testing and Materials "ASTM D7042 - 16e3: Standard Test Method for Dynamic Viscosity and Density of Liquids by Stabinger Viscometer (and the Calculation of Kinematic Viscosity)", ASTM, West Conshohocken, Pennsylvania, United States, 2016.

[22] International Organization for Standardization "ISO 12185:1996: Crude petroleum and petroleum products - Determination of density - Oscillating U-tube method", ISO, Geneva, Switzerland, 1996, Corrigenda 1: 2001.

[23] Barabás, I., Molea, A., Suciu, R. "Fuel Properties of DieselEthanol-Tetrahydrofuran Blends: Experimental and Theoretical Approaches", In: Burnete, N., Varga, B. (eds.) Proceedings of the 4th International Congress of Automotive and Transport Engineering (AMMA 2018), Springer, Cham, Switzerland, 2019, pp. 197-208.

https://doi.org/10.1007/978-3-319-94409-8_24

[24] Barabás, I. "Predicting the temperature dependent density of biodiesel-diesel-bioethanol blends", Fuel, 109, pp. 563-574, 2013. https://doi.org/10.1016/j.fuel.2013.03.001

[25] Yuan, W., Hansen, A. C., Zhang, Q., Tan, Z. "Temperaturedependent kinematic viscosity of selected biodiesel fuels and blends with diesel fuel", Journal of the American Oil Chemists' Society, 82(3), pp. 195-199, 2005. https://doi.org/10.1007/s11746-005-5172-6

[26] Gülüm, M., Bilgin, A. "Two-term power models for estimating kinematic viscosities of different biodiesel-diesel fuel blends", Fuel Processing Technology, 149, pp. 121-130, 2016.

https://doi.org/10.1016/j.fuproc.2016.04.013

[27] Das, M., Sarkar, M., Datta, A., Santra, A. K. "Study on viscosity and surface tension properties of biodiesel-diesel blends and their effects on spray parameters for CI engines", Fuel, 220, pp. 769-779, 2018. https://doi.org/10.1016/j.fuel.2018.02.021

[28] Prajapati, A. N. "Performance and emission studies of ethanol-diesel blend in an unmodified diesel engine with tetrahydrofuran as a surfactant", MSc Thesis, Delhi Technological University, 2018. [online] Available at: http://14.139.251.106:8080/jspui/bitstream/ repository/16381/1/ADITYA\%20MTECH\%202K16THE04.pdf [Accessed: 01 October 2019] 